\title{
Genetic Characterization of Some Cyanobacterial Species Using by RAPD-PCR Technique
}

\author{
Mehmet Karaca (Corresponding author) \\ Aksaray University, Faculty of Science and Letters, Department of Biology, \\ 68100 Aksaray, Turkey \\ E-mail: mkaraca@aksaray.edu.tr \\ ORCID ID: https://orcid.org/0000-00027688-4223 \\ Kadir Aricak \\ Aksaray University, Faculty of Science and Letters, Department of Biology, \\ 68100 Aksaray, Turkey \\ E-mail: aricakkadir@msn.com \\ Fatma Gurbuz \\ Aksaray University, Faculty of Engineering, Department of Environmental Engineering, \\ 68100 Aksaray, Turkey \\ E-mail: fatma_gurbuz@yahoo.com
}

\begin{abstract}
Cyanobacteria are the ecologically important organisms due to they thrive in wide variety of habitats and some with the ability to produce secondary metabolites known as cyanotoxin. Besides classical identification methods, DNA fingerprint and many other PCR based molecular approaches have being adopted and well used in the molecular systematics and genetic characterization of Cyanobacteria. In this study, 7 bacterial isolates were analyzed through the RAPD-PCR technique using 15 different randomly selected primers. All the bacterial isolates were produced 306 completely polymorphic amplification products. A minimum 12 and maximum 35 different PCR fragments were obtained by the OPA-14 and Hip-GC primers respectively. The size of RAPD-PCR fragments were varied between 175-3.000 bp. Two different dendrogrames (UPGMA ve Neighbor Joining) were created using Nei's genetic distance and similarity values, to identify genetic relationships among analyzed bacterial isolates. According to the results, the Synechococcus elongatus and Pseudoanabaena moniliformis are defined as the most distant species, while the Anabaena affisinis and Arthrospira sp. are determined as the closest organisms. Consequently, randomly selected primers have generated $100 \%$ polymorphic fragments, indicating high efficiency and successful utilization of RAPD-PCR technique in the genetic characterizations and molecular systematics of different Cyanobacteria isolates.
\end{abstract}

Keywords: Cyanobacteria, genetic characterization, DNA polymorphism, RAPD-PCR technique.

DOI: $10.7176 /$ JSTR/6-09-09

\section{RAPD-PCR Tekniği Kullanılarak Bazı Siyanobakteriyel Türlerin Genetik Karakterizasyonu}

Özet

Çok çeşitli yaşam alanlarında gelişmeleri ve bazılarının siyanotoksin olarak bilinen ikincil metabolitleri üretme yeteneklerinden dolayı Siyanobakteriler, ekolojik açıdan oldukça önemli organizmalardır. $\mathrm{Bu}$ canlıların sınıflandırılmaları ve tanımlanmaları oldukça karmaşıktır. Klasik tanımlama yöntemlerinin

92 I P a g e

www.iiste.org 
yanısıra, Siyanobakterilerin moleküler sistematiği ve genetik karakterizasyonunda DNA parmakizi ve birçok PCR temelli moleküler yaklaşımlar benimsenmeye ve kullanılmaya başlanmıştır. Bu çalışmada toplam 7 Siyanobakteri izolatı, 15 farklı random primer kullanılarak RAPD-PCR tekniği ile analiz edilmiştir. Tüm bakteriyel izolatlar, tamamı polimorfik olan 306 amplifikasyon ürünü oluşturmuştur. En az 12 ve en fazla 35 farklı PCR fragmenti sırasıyla OPA-14 ve Hip-GC primerleri ile elde edilmiştir. RAPD-PCR fragmentlerinin büyüklüğü 175-3.000 bç arasında değişmektedir. Bakteri izolatları arasındaki genetik akrabalık ilişkisini ortaya çıkarmak için Nei's genetik uzaklık ve benzerlik değerleri kullanarak iki farklı dendrogram (UPGMA ve Neighbor Joining) oluşturulmuştur. Bu verilere göre Synechococcus elongatus ve Pseudoanabaena moniliformis en uzak türler, Anabaena affisinis ve Arthrospira sp. ise birbirine en yakın organizmalar olarak tespit edilmiştir. Sonuç olarak, seçilen RAPD primerlerinin \%100 polimorfik fragmentler oluşturduğu ve RAPD-PCR tekniğinin farklı Siyanobakteri izolatlarının genetik karakterizasyonunda ve moleküler sistematiğinde etkin ve başarılı bir şekilde kullanılabileceği görülmüştü.

Anahtar Kelimeler: Siyanobakteri, genetik karakterizasyon, DNA polimorfizmi, RAPD-PCR tekniği.

\section{GİRiș}

Prokaryotik hücre yapısına sahip fotosentetik Siyanobakterilerin (mavi-yeşil bakteri ya da mavi-yeşil alg) varlığı günümüzden yaklaşık 3.5 milyar yıl öncesine kadar uzanmaktadır (Oinam et al. 2011). Gram-negatif bakterilerin genel özelliklerine sahip olan Siyanobakteriler değişik sucul ortamlarda, karada, kutup bölgelerinde, çöllerde ve çok sıcak su kaynakları gibi farklı habitatlarda yaşayabilirler (Ionescu et al. 2010). Cins ve tür sayısı üzerine sistematik tartışmalar devam ediyor olmasına rağmen (2000-8000 arasında olduğu düşünülüyor), mevcut taksonomiye göre 347 cins ve 2698 tür tanımlanmıştır (Nabout et al. 2013). İnsan ve hayvan sağlığı için zararlı olan ve toksisitelerine göre hepatotoksin, nörotoksin, sitotoksin, dermatotoksin ve irritant olarak bilinen değişik siyanotoksinleri üretirler (Dittmann et al.2013, Moreira et al. 2014). Siyanobakteriler değişik fotosentetik pigmentler içermeleri nedeniyle denizlerin temel besin kaynağını oluşturan ve atmosferik azotu da asimile ederek diğer organizmaların kullanabileceği mineral azota dönüştürebilen organizmalardır (Demoulin et al. 2019). Ayrıca, yeryüzünde fikse edilen toplam karbonun yaklaşık \%20-30'luk bir kısmının sadece bu bakterilerce sağlandığı düşünülmektedir. Tek ve çok hücreli serbest yaşayabilenleri olduğu gibi, müsilaj bir zarla koloni oluşturan Siyanobakteriler de vardır. Siyanobakterilerin geniş yaşam alanına sahip olmaları, yüksek çeşitlilik gösteren türlerinin olması ekolojik açıdan bu organizmaları önemli kılmaktadır. Fenotipik (morfolojik, fizyolojik) ve ekolojik varyantları çok çeşitlilik gösteren Siyanobakterilerin tanımlanması, sınıflandırılması zor ve karışıktır. Siyanobakteriler gelişmesi (bölünme modeli ve üreme tipi), yapısı (trikom tipi ve büyüklüğü, hücre düzenlenmesi ve büyüklüğü, bölünme düzlemi, heterosist ve akinet oluşumu, hareketlilik, toksisite gösterip-göstermemesi, gaz vakuolu varlığı, hücre duvarı ve tiylakoid yapısı gibi değişik hücre bileşenlerinin varlığı) ve fizyolojisi (kromatik adaptasyon, tuzluluğa tolerans ve vitamin ihtiyacı gibi) gibi fenotipik özellikleri dikkate alınarak sınıflandırılmaya çalışılmıştır (Rippka et al. 1979, Komarek and Anagnostidis 1989, Baker 1992, Keshari and Das 2015). Ancak bu tip geleneksel tanımlamalar yetersiz kalabilmekte, çevresel şartlardan ve kültür ortamından çok etkilenebilmektedirler (Lyra et al. 2005, Rajaniemi et al. 2005). İzolasyon ve biyokimyasal tanımlama (lipid ve yağ asidi kompozisyonu, izozim modeli, pigmentasyon durumu) gibi metotlar ve optikal, epifluoresans veya elektron mikroskopisi gibi morfolojik kriterler bu organizmaları oldukça zor ayırt etmekte ve çoğunluğu sınıf düzeyinde kalmaktadır (Holton et al. 1968, Weeden et al. 1982, Smit et al. 1983, Ziegler et al. 1998, Cox et al. 2004, Sarsekeyeva et al. 2014). Mikrobiyal biyoçeşitlilikteki yetersizlikleri aşmak ve eksiklikleri giderebilmek için son 20 y1llık bir süreçte çok değişik DNA temelli moleküler biyoloji tekniği geliştirilmiş ve bu yöntemler kullanılarak doğal mikrobiyal kommünitelerin genetik karakterizasyonları, biyoçeşitlilik analizleri ve kommünite yapılarının izlenmesi gerçekleştirilmiştir (Garcia-Pichel et al. 2001, Redfield et al. 2002). DNA molekülünü temel alan moleküler filogenetik sınıflandırma teknikleri özellikle problemli grupların

93 I P a g e

www.iiste.org 
sınıflandırılmasında, toksin üreten türlerin teşhisinde ve tespitinde değerli veriler ortaya koyabilmekte, moleküler genetik analiz sonuçları temel alınarak taksonların sistematikteki yeri değişebilmektedir.

DNA belirteçleri (DNA marker), moleküler sistematik çalışmalarında moleküler biyolojinin başvurduğu önemli araçlardan birini temsil etmekte ve etkin gelişmelere olanak sağlamaktadır. DNA belirteçleri, farklı genotipler arasındaki dizi polimorfizmini gösteren özgül genom bölgeleridir. Genel olarak DNA'yı temel alan belirteç sistemleri, diğer belirteç sistemlerinden; güvenilir olmaları, tekrarlanabilir olmaları, çevresel koşullardan ve değişimlerden etkilenmemeleri, tüm canl, doku ve hücresel düzeyde saptanabilmeleri, allel frekanslarının daha yüksek olması, çoğunlukla kodominant kalıtım göstermeleri gibi özellikler bakımından üstündürler. DNA belirteçlerinden restriksiyon enzim kesimi (RFLP ve ARDRA) (Laloui et al. 2002, Neilan 2002, Margheri et al. 2003, Valerio et al. 2009, Chakdar and Pabbi 2012), 16S rDNA (Keshari et al. 2016, Sciuto and Moro 2016, Shiels et al. 2019), ITS (Laloui et al. 2002) ve değişik mikrosistin genleri dizi analizleri (Ma et al. 2004, Marquardt and Palinska 2007) veya PCR temelli olanlar (Neilan 1995, Casamatta et al. 2003, Shalini et al. 2008, Oinam et al. 2011) Siyonabakteri moleküler genetiğinde sıklıkla kullanılmıştır. Özellikle RAPD-PCR (Nishihara et al. 1997, Thajuddin and Muralitharan 2008, Palinska et al. 2011, Prabakaran et al. 2011, Afaf et al. 2012), REP-PCR (Katayama et al. 2002, Muralitharan and Thajuddin 2011), STRR-PCR (Guevara et al. 2002, Selvakumar and Gopalaswamy 2008, Muralitharan and Thajuddin 2011, Afaf et al. 2012) ve ERIC-PCR (Rasmussen and Svenning 1998, Lyra et al. 2001, Valerio et al. 2005, Bruno et al. 2006) gibi PCR temelli olan genetik belirteçlerin kullanılmasıyla değişik biyolojik sorunların çözümünde hız kazanılmış ve taksonomik düzeylerde önemli bilgiler elde edilmiştir. Bu belirteç sistemleri karşılaştırıldığında RAPD tekniği ilgilenilen taksonun genleriyle ilgili herhangi bir ön bilgi gerektirmemesi nedeniyle en avantajllarından birisidir. RAPD yöntemi, rastgele seçilmiş 9-10 nükleotitlik bir primerin ilgili taksona ait DNA molekülüne bağlanarak PCR ile çoğaltılması ve elde edilen PCR ürünlerinin jel elektroforezinde görüntülenerek sonuçların değerlendirilmesi işlemine dayanır. Ayrıca ucuz ve tekrarlanabilir olması da tekniğin diğer bir avantajıdır. Siyanobakterilerle yapılmış olan birçok çalışmada RAPD-PCR tekniği sonucu elde edilen DNA profillerinin mevcut türlerin ayrımında kullanılabilirliği ortaya konmuştur (Neilan 1995, Nishihara et al. 1997, Shalini et al. 2007, Praveen Kumar et al. 2009, Prabakaran et al. 2011, Afaf et al. 2012).

RAPD-PCR, özellikle akraba organizmalar arasındaki DNA dizi farklılığının ortaya çıkarılmasında yaygın şekilde kullanılmakta ve elde edilen nükleotit farklılıkları RAPD belirteçleri olarak isimlendirilmektedir. Yöntemde, spesifik bir DNA bölgesi değil, genom üzerinde birçok DNA lokusu aynı anda çoğaltılabilmektedir. Genomlar arasında RAPD belirteç farklılı̆ının nedenleri, primer bağlanma bölgesini değiştiren (veya ortadan kaldıran) tek nükleotit değişiklikleri ya da insersiyonlar/delesyonlar olabileceği gibi, amplifikasyona imkan vermeyecek şekilde primer bağlanma bölgelerini ayıran genomik dizilerde meydan gelen insersiyonlar da olabilmektedir (Okore et al. 2017).

\section{Materyal ve Yöntem}

\subsection{Siyanobakteri türleri}

Siyanobakteri türleri daha önceden yapılan bir TÜBİTAK çalışmasında (Proje No: 105 O 053) morfolojik ve biyokimyasal olarak tanımlanmıştır (Gurbuz et al. 2009). Pasteur kültür koleksiyonundan elde ettiğimiz Microcystis aeruginosa (PCC 7806) ve diş pozitif kontrol örneği olarak ise Pseudomonas aeroginosa (ATCC 27853) türleri de çalışmada kullanılmıştır.

\subsection{Genomik DNA izolasyonu}

Siyanobakteri genomik DNA izolasyonu, Thermo Scientific GeneJET Genomic DNA Purification Kiti kullanılarak ve minör modifikasyonlar yapılarak gerçekleştirilmiştir. Genomik DNA örneklerinin konsantrasyonları nanodropta ölçülmüş ve son konsantrasyon $50 \mathrm{ng} / \mu 1$ olacak şekilde sulandırılmıştır. 


\subsection{RAPD primerleri}

RAPD-PCR aşamasında Thermo Fisher Scientific firması (Offenbach/Almanya) tarafindan sentez edilen 10 baz uzunluğunda, 15 adet RAPD primeri kullanılmıştır (Tablo 1).

Tablo 1. RAPD-PCR reaksiyonlarında kullanılan primer dizileri, Tm dereceleri $\left({ }^{\circ} \mathrm{C}\right)$ ve $\%$ GC oranları

\begin{tabular}{|c|c|c|c|}
\hline Primer & Dizi $\left(\mathbf{5}^{\prime} \rightarrow \mathbf{3}\right.$ ') & \% GC & Tm \\
\hline CRA-22 & CCGCAGCCAA & 70 & 34 \\
\hline CRA-25 & AACGCGCAAC & 60 & 32 \\
\hline Hip-CA & GCGATCGCCA & 70 & 34 \\
\hline OPA-11 & CAATCGCCGT & 60 & 32 \\
\hline OPA-13 & CAGCACCCAC & 70 & 34 \\
\hline Hip-GC & GCGATCGCGC & 80 & 36 \\
\hline Hip-TG & GCGATCGCTG & 70 & 34 \\
\hline MM & TCACGGTGCA & 60 & 32 \\
\hline CRA-23 & GCGATCCCCA & 70 & 34 \\
\hline CRA-26 & GTGGATGCGA & 60 & 32 \\
\hline OPA-08 & GTGACGTAGG & 60 & 32 \\
\hline OPA-18 & AGGTGACCGT & 60 & 32 \\
\hline OPA-12 & TGTCATCCCC & 60 & 32 \\
\hline OPA-14 & TGCGTGCTTG & 60 & 32 \\
\hline OPA-15 & GACGGATCAG & 60 & 32 \\
\hline
\end{tabular}

\subsection{RAPD-PCR döngü koşulları}

Deneysel verilerin güvenilirliği ve tekrarlanabilirliği için, PCR reaksiyonlar en az iki kere tekrar edilmiş ve her bir primere ait sabit bant profili veren reaksiyon koşulları seçilmiştir. Döngü şartları; ön denatürasyon $95^{\circ} \mathrm{C} 3$ dak, denatürasyon $95^{\circ} \mathrm{C} 45 \mathrm{sn}$, bağlanma (annealing) $32-36^{\circ} \mathrm{C} 45$ sn (Tablo 1), uzama (extention) $72^{\circ} \mathrm{C} 45 \mathrm{sn}$ ve son uzama ise $72^{\circ} \mathrm{C} 5$ dak olacak şekilde ayarlanmıştır. Denatürasyon, bağlanma ve uzama olarak bilinen PCR döngüleri toplamda 45 döngü yapılmıştır.

\subsection{Dendrogram çizimi}

Dendrogram çizimi için jellerdeki bantlar monomorfik ve polimorfik özellikleri açısından değerlendirilmiştir. PCR ürünlerinin bant büyüklükleri DNA size marker (Fermentas GeneRuler 100 bp Plus DNA ladder) kullanılarak hesaplanmıştır. Elde edilen bantlar monomorfik ise 0, polimorfik ise 1 olarak değerlendirilmiştir. Bu sayısal matriks bilgisi Genetic Analysis in Excel 6.501 (GenAlEx) programı kullanılarak (Peakall et al. 2012) Nei's genetik uzaklık ve benzerlik değerleri elde edilmiştir. Bir sonraki aşamada ise iki farklı dendrogram (UPGMA ve Neighbor Joining) genetik uzaklık ve benzerlik değerleri temel alınarak MEGA (Molecular Evolutionary Genetics Analysis) 6.06 programı kullanılarak çizilmiştir.

\section{Bulgular}

Genetik karakterizasyon amaçlı kullanılan 15 farklı RAPD primeri ile toplam 306 adet amplifikasyon ürünü elde edilmiştir. Bantların tamamının (\%100) polimorfik olduğu görülmüştür (Tablo 2). En düşük bant ağırlığına sahip polimorfik PCR ürünü 175 bç (baz çifti) ile CRA-26 primerinden, en büyük bant ağırlığına sahip polimorfik PCR ürünü ise, 3.000 bç ile CRA-25 ile OPA-13 primerlerinden alınmıştır. Polimorfik primer başına elde edilen ortalama bant sayısı 20.4 (306/15) olarak tespit edilmiştir. En fazla polimorfik RAPD belirteci oluşturan primer ise 35 farklı PCR ürünü ile Hip-GC primeri olmuştur (Şekil 1). Bakteri örneklerinin genetik akrabalık ilişkisini ortaya çıkarmak için Nei’s genetik uzaklık ve benzerlik değerleri kullanılarak iki farklı dendrogram (UPGMA ve Neighbor Joining) çizilmiştir (Şekil

95 I P a g e

www.iiste.org 
2 ve 3). Genetik uzaklık değerleri temel alındığında, 0.451 değeri ile Synechococcus elongatus ve Pseudoanabaena moniliformis en uzak türler, 0.268 değeri ile Anabaena affisinis ve Arthrospira sp. ise birbirine en yakın taksonlar olarak tespit edilmiştir (Tablo 3). Genetik benzerlik değerleri temel alındığında da yine aynı türler 0.765 değeri ile en yakın ve 0.637 değeri ile en uzak türler olarak tespit edilmişlerdir (Tablo 4). UPGMA ile çizilen dendrogramda ise dış tür olarak kullandığımız pozitif kontrol örneği Pseudomonas aeroginosa genetik olarak ilk ayrılan türdür. Daha sonra ise sirasıyla Synechococcus elongatus, Phormidium formosum, Microcystis aeruginosa (PCC 7806), Plankthorix limnetica, Pseudoanabaena moniliformis, Arthrospira sp. ve Anabaena affisinis ayrılmaktadır (Şekil 3).

Tablo 2. RAPD-PCR reaksiyonlarından elde edilen bant karakteristikleri

\begin{tabular}{|c|c|c|c|c|c|}
\hline Primer & $\begin{array}{c}\text { Bant } \\
\text { büyüklüğü } \\
\text { (bç) }\end{array}$ & $\begin{array}{c}\text { Toplam } \\
\text { bant sayısı }\end{array}$ & $\begin{array}{c}\text { Monomorfik } \\
\text { bant sayısı }\end{array}$ & $\begin{array}{l}\text { Polimorfik } \\
\text { bant sayısı }\end{array}$ & $\begin{array}{c}\text { Polimorfizm } \\
\text { oranı (\%) }\end{array}$ \\
\hline CRA-22 & $250-2.000$ & 29 & - & 29 & 100 \\
\hline CRA-23 & $225-2.750$ & 21 & - & 21 & 100 \\
\hline CRA-25 & $375-3.000$ & 19 & - & 19 & 100 \\
\hline CRA-26 & $175-1.500$ & 22 & - & 22 & 100 \\
\hline Hip-CA & $275-2.600$ & 25 & - & 25 & 100 \\
\hline Hip-GC & $225-1.800$ & 35 & - & 35 & 100 \\
\hline Hip-TG & $250-1.800$ & 28 & - & 28 & 100 \\
\hline MM & $175-2.400$ & 15 & - & 15 & 100 \\
\hline OPA-08 & $200-1.900$ & 17 & - & 17 & 100 \\
\hline OPA-11 & $250-2.500$ & 19 & - & 19 & 100 \\
\hline OPA-12 & $250-1.600$ & 13 & - & 13 & 100 \\
\hline OPA-13 & $330-3.000$ & 18 & - & 18 & 100 \\
\hline OPA-14 & $275-2.800$ & 12 & - & 12 & 100 \\
\hline OPA-15 & $275-1.800$ & 18 & - & 18 & 100 \\
\hline OPA-18 & $200-2.200$ & 15 & - & 15 & 100 \\
\hline Toplam & - & 306 & - & 306 & - \\
\hline
\end{tabular}




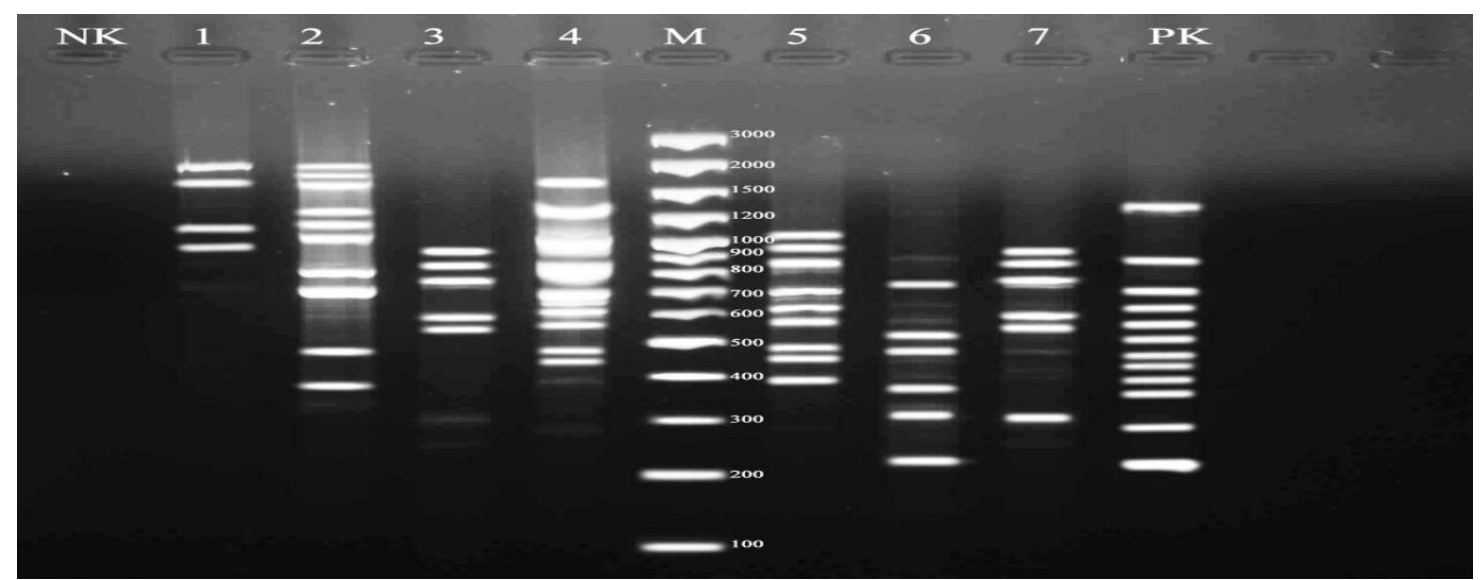

Şekil 1. Hip-GC primeri kullanılarak elde edilen RAPD-PCR ürünlerinin agaroz jeldeki görüntüsü. 1; Microcystis aeruginosa, 2; Synechococcus elongatus, 3; Anabaena affisinis, 4; Phormidium formosum, 5; Plankthorix limnetica, 6; Pseudoanabaena moniliformis, 7; Arthrospira sp., PK; Pseudomonas aeroginosa, NK; Negatif kontrol, M; 100 bp DNA size marker
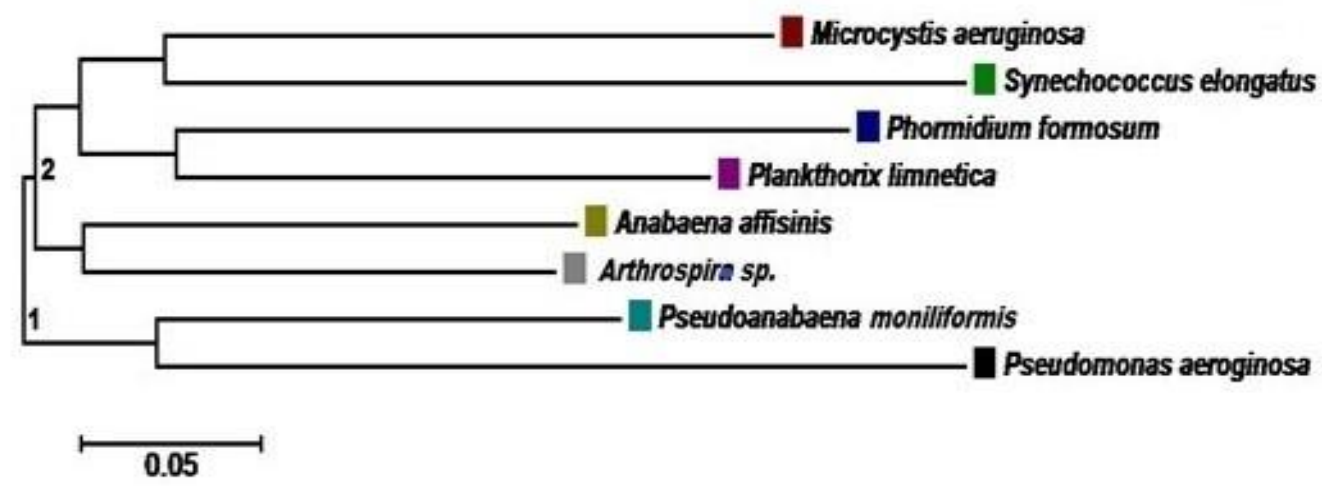

Şekil 2. Neighbor-Joining ile çizilen dendrogram
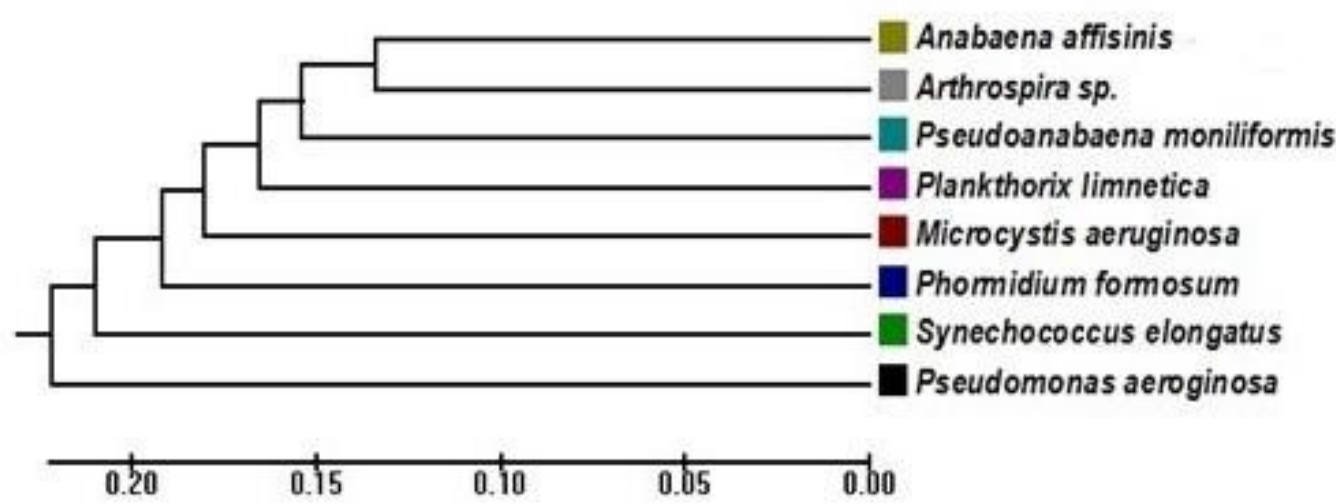

Şekil 3. UPGMA ile çizilen dendrogram 
Tablo 3. Nei’s genetik uzaklık matriksi değerleri

\begin{tabular}{|c|c|c|c|c|c|c|c|c|}
\hline Örnek & 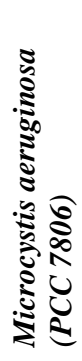 & 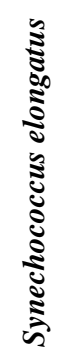 & 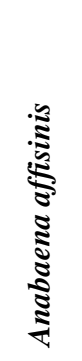 & 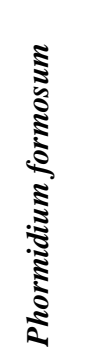 & 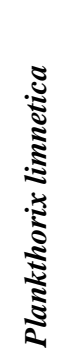 & 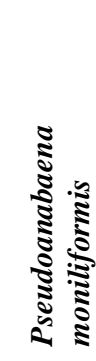 & 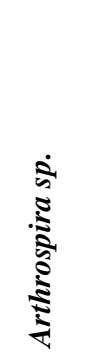 & 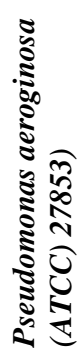 \\
\hline $\begin{array}{l}\text { Microcystis aeruginosa } \\
\text { (PCC 7806) }\end{array}$ & 0.000 & & & & & & & \\
\hline Synechococcus elongatus & 0.391 & 0,000 & & & & & & \\
\hline Anabaena affisinis & 0.339 & 0.372 & 0.000 & & & & & \\
\hline Phormidium formosum & 0.396 & 0.440 & 0.396 & 0.000 & & & & \\
\hline Plankthorix limnetica & 0.372 & 0.445 & 0.335 & 0.335 & 0.000 & & & \\
\hline $\begin{array}{l}\text { Pseudoanabaena } \\
\text { moniliformis }\end{array}$ & 0.396 & 0.451 & 0.339 & 0.386 & 0.335 & 0.000 & & \\
\hline Arthrospira sp. & 0.339 & 0.420 & 0.268 & 0.405 & 0.325 & 0.277 & 0.000 & \\
\hline $\begin{array}{l}\text { Pseudomonas aeroginosa } \\
\text { (ATCC 27853) }\end{array}$ & 0.482 & 0.509 & 0.430 & 0.471 & 0.456 & 0.353 & 0.410 & 0.000 \\
\hline
\end{tabular}

Tablo 4. Nei's genetik benzerlik matriksi değerleri

\begin{tabular}{|c|c|c|c|c|c|c|c|c|}
\hline Örnek & 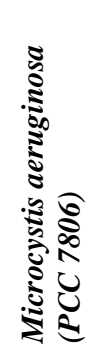 & 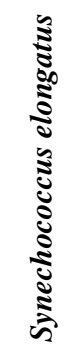 & 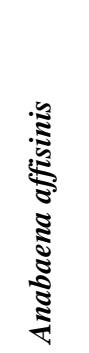 & 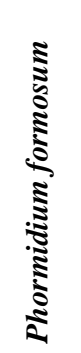 & 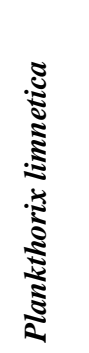 & 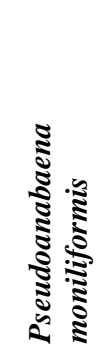 & 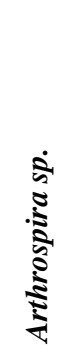 & 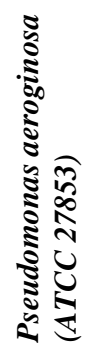 \\
\hline $\begin{array}{l}\text { Microcystis aeruginosa } \\
\text { (PCC 7806) }\end{array}$ & 1.000 & & & & & & & \\
\hline Synechococcus elongatus & 0.676 & 1.000 & & & & & & \\
\hline Anabaena affisinis & 0.712 & 0.690 & 1.000 & & & & & \\
\hline Phormidium formosum & 0.673 & 0.644 & 0.673 & 1.000 & & & & \\
\hline Plankthorix limnetica & 0.690 & 0.641 & 0.716 & 0.716 & 1.000 & & & \\
\hline $\begin{array}{l}\text { Pseudoanabaena } \\
\text { moniliformis }\end{array}$ & 0.673 & 0.637 & 0.712 & 0.680 & 0.716 & 1.000 & & \\
\hline Arthrospira sp. & 0.712 & 0.657 & 0.765 & 0.667 & 0.722 & 0.758 & 1.000 & \\
\hline $\begin{array}{l}\text { Pseudomonas aeroginosa } \\
\text { (ATCC 27853) }\end{array}$ & 0.618 & 0.601 & 0.650 & 0.624 & 0.634 & 0.703 & 0.663 & 1.000 \\
\hline
\end{tabular}


Neighbor-Joining ile çizilen dendrogram sonuçlarına göre iki ana grup oluşmaktadır. Dendrogramın birinci grubu Pseudomonas aeroginosa ve Pseudoanabaena moniliformis örneklerini kapsarken, çalışılan diğer örnekler ikinci grup içinde yer almaktadır (Şekil 2).

\section{Sonuç ve Öneriler}

Bu çalışma kapsamında daha önce morfolojik ve biyokimyasal olarak tanımlanan ve sınıflandırılan bazı Siyanobakteri izolatlarının genetik karakterizasyonu, RAPD-PCR tekniği kullanılarak gerçekleştirilmiştir. Siyanobakteriler, taksonomik olarak oldukça çeşitlilik gösteren büyük bir gruptur. Sınıflandırmalarında morfolojik ve diğer fenotipik özellikler yaygın olarak kullanılmıştır. Son yıllarda uygulanan moleküler filogenetik sinıflandırma teknikleri özellikle problemli grupların sınıflandırılmasında, toksin üreten türlerin teşhisinde ve tespitinde değerli veriler ortaya koyabilmekte, moleküler genetik analiz sonuçları temel alınarak taksonların sistematikteki yeri değişebilmektedir.

RAPD, farklı Siyanobakteri gruplarını tanımlamada ve genetik çeşitlilik analizlerinde kullanılan bir tekniktir. Neilan et al. (1995) Anabaena ve Microcystis cinslerinin, Nishihara et al. (1997) Microcystis cinsine ait değişik türlerin, Casamatta et al. (2003) Phormidium retzii suşlarının, Martinez et al. (2006) Alexandrium tamarense ve Alexandrium minutum suşlarının, Srivastava et al. (2007) 4 farklı cinsin, Shalini and Gupta (2008) 30 Calothrix suşunun, Singh (2008), Perumal et al. (2009) 8 Oscillatoria ve 4 Lyngbya suşunun, Hube et al. (2009) Nodularia harveyana ve Oscillatoria brevis suşlarının, Palinska et al. (2011) Phormidium suşlarının, Muralitharan and Thajuddin (2011) Synechococcus elongatus suşlarının, Singh and Dhar (2014) Spirulina ve akraba cinslerinin, Arima et al. (2012) Nostoc commune genotiplerinin, Keithellakpam et al. (2015) 4 farklı Siyanobakteri cinsini ve bu cinslere ait suşların, Chakdar et al. (2017) 20 Nostoc suşunun DNA düzeyinde genetik karakterizasyonu, genetik çeşitliliği, DNA fingerprint temelli moleküler sistematiğinde ve filogenisinde bizimde çalışmalarımızda kullanmış olduğumuz primerlerin (CRA-22, CRA-23, CRA-26, Hip-TG, Hip-GC, OPA-08, OPA-11 ve OPA-13 başta olmak üzere) büyük bir kısmını kullanarak intra-spesifik ve inter-spesifik düzeyde başarılı moleküler genetik analizler yapmışlardır. Ayrıca Shalini et al. (2007), Perumal et al. (2009), Premanandh et al. (2009), Prabakaran et al. (2011) ve Chakdar et al. (2017) RAPD çalışmalarında kullandıkları random primerler ile $\% 100$ polimorfizm oranı ve oldukça düzgün bantlaşma modelleri elde etmişlerdir. $\mathrm{Bu}$ çalışmalardaki mevcut bulgular bizim deneysel sonuçlarımızla da uyumludur. Salem et al. (2019) farklı stres koşulları altında, Anabaena turolosa'nın farklı tipleriyle yapmış olduğu çalışmada bizimde kullanmış olduğumuz dört farklı primer ile (OPA-11, OPA-13, CRA-22 ve Hip-TG) RAPD reaksiyonları gerçekleştirmiş ve DNA polimorfizm oranını \%43.75 olarak bulmuştur. Polimorfizm oranının düşüklüğü ise; değişik stres koşullarının DNA dizisinde değişiklik yaptığı ve bu değişimlerinde polimorfizm oranını etkilediği şeklinde açıklamıştır. Çalışmamızda istatiksel analizlerin güvenilirliği açısından primer sayısı artırılarak 15 farklı random primer çalışılmıştır. Çalışmanın deneysel aşamalarında PCR reaksiyonlarının en az iki kez tekrar edilmesi ve sonuçların değerlendirilmesinde polimorfik bant modellerinin dikkate alınması ile deneysel hatalar en aza indirilmiştir. RAPD çalışmalarında polimorfizm oranının değişkenliğini, kullanılan primer sayısı da etkileyebilmektedir. Primer sayısının fazla olması daha fazla lokusun taranmasına olanak sağladığı için RAPD tekniğinin istatiksel değerini ve RAPD reaksiyonlarının verimliliğini artırmaktadır.

RAPD-PCR tekniğinin genetik analizlerde etkili bir yöntem olduğu ve genom analizlerinde başarılı şekilde uygulandığı birçok çalışmada vurgulanmıştır. RAPD ile kodlayıcı ve kodlayıcı olmayan DNA dizilerinin rastgele primerlerle taranabilmesi, yüksek düzeyde genetik varyasyonun saptanmasına olanak vermektedir. Deneysel veriler sonucunda; çalışmalarımızda kullandığımız RAPD-PCR tekniğinin ve kullanılan RAPD primerlerin ülkemizin iki farklı gölünden (Kovada Gölü/Isparta ve Titreyen Göl/Alanya) toplanan Siyanobakteri izolatlarının genetik karakterizasyonunda, teşhisinde, tanımlamasında, genetik çeşitlilik analizinde ve moleküler sistematiğinde başarılı bir şekilde kullanılabileceği görülmüştür. Kullanılan primerlerle elde edilen amplifikasyon ürünlerinin sayısı ve polimorfizm yüzdesi, RAPD-PCR ürünlerinin değişik programlarla analizi ve dendrogramlar sonucu

99 | P a g e

www.iiste.org 
ortaya çıkan genetik yapı morfolojik karakterizasyon ile de uyumlu bir tablo ortaya koymaktadır. Kullanılan izolatlar biri dişında (Arthrospira sp.) tür düzeyinde tanımlama yapılmış̧ır.

RAPD primerleri kullanarak yapılan mevcut çalışma, aynı yöntemle yapılan diğer çalışmaların verileriyle kıyaslandığında; RAPD-PCR tekniğinin Siyanobakteri moleküler sistematiğinde başarılı bir şekilde kullanılabileceğini ortaya koymaktadır. Bu çalışma Siyanobakteri izolatlarının biyolojik çeşitliliği ve genetik karakterizasyonuyla ilgili ülkemizde yapılması planlanan diğer çalışmalar için de temel oluşturabilecek bir çalışma niteliği taşımaktadır.

\section{Teşekkür}

Aksaray Üniversitesi BAP Koordinörlüğünün 2013/50 No'lu projesi ile maddi olarak desteklenmiş olan deneysel çalışmalar ASÜBTAM-Moleküler Biyoloji ve Metabolizma Laboratuvarında gerçekleştirilmiştir. Desteklerinden dolayı Aksaray Üniversitesi Rektörlüğüne, BAP Koordinörlüğüne ve Biyoistatistik programlarının kullanımındaki yardımlarından dolayı Doç. Dr. Tolga KANKILIÇ’a teşekkür ederiz.

\section{Kaynaklar}

Afaf, S.I., Al-Hazzani, A., Arif, A.I. \& Brian, M. (2012). Molecular characterization of some toxigenic Cyanobacteria by PCR-based techniques. Science Journal of Microbiology, 2012, 117. https://doi: $10.7237 / \mathrm{sjmb} / 224$

Arima, H., Horiguchi, N., Takaichi, S., Kofuji, R., Ishida, K.I., Wada, K. \& Sakamoto, T. (2012). Molecular genetic and chemotaxonomic characterization of the terrestrial cyanobacterium Nostoc commune and its neighboring species. FEMS Microbiology Ecology, 79 (1), 34-45. https://doi.org/ 10.1111/j.1574-6941.2011.01195.x

Baker, P. (1992). Identification of common noxious cyanobacteria. Part II-Chroococcales, Oscillatoriales. -Urban Water Research Association of Australia, Research Report No. 46: 1139. Melbourne Water Corporation, Australia

Bruno, L., Billi, D., Albertano, P. \& Urzi, C. (2006). Genetic characterization of epilithic cyanobacteria and their associated bacteria. Geomicrobiology Journal, 23 (5), 293-299. https://doi.org/10.1080/01490450600760732

Casamatta, D.A., Vis, M.L. \& Sheath, R.G. (2003). Cryptic species in cyanobacterial systematics: a case study of Phormidium retzii (Oscillatoriales) using RAPD molecular markers and 16S rDNA sequence data. Aquatic Botany, $77 \quad$ (4), 295-309. https://doi.org/10.1016/j.aquabot.2003.08.005

Chakdar, H. \& Pabbi, S. (2012). Morphological characterization and molecular fingerprinting of Nostoc strains by multiplex RAPD. Microbiology, 81 (6), 710-720. https://doi.org/ $10.1134 /$ S0026261712060070

Chakdar, H. \& Pabbi, S. (2017). A comparative study reveals the higher resolution of RAPD over ARDRA for analyzing diversity of Nostoc strains. 3 Biotech, 7 (125), 1-10. https://doi.org/ 10.1007/s13205-017-0779-5

Cox, P.A., Banack, S.A., Murch, S.J., Rasmussen, U., Tien, G., Bidigare, R.R., Metcalf, J.S., Morrison, L.F., Codd, G.A. \& Bergman, B. (2004). Diverse taxa of cyanobacteria produce Nmethylamino L-alanine, a neurotoxic amino acid. Proceedings of the National Academy of Sciences, 102 (1), 5074-5078. https://doi.org/10.1073/pnas.0501526102

Demoulin, C.F., Lara Y.J., Cornet, Luc., François, C., Baurain, D., Wilmotte, A. \& Javaux, E.J. (2019). Cyanobacteria evolution: Insight from the fossil record. Free Radical Biology \& Medicine, 140, 206-223. https://doi.org/10.1016/j.freeradbiomed.2019.05.007

$100 \mid \mathrm{P}$ a g e

www.iiste.org 
Dittmann, E., Fewer, D.P. \& Neilan, B.A. (2013). Cyanobacterial toxins: Biosynthetic routes and evolutionary roots. FEMS Microbiology Reviews, 37, 23-43. https://doi.org/10.1111/j.15746976.2012.12000.x

Garcia-Pichel, F., Cortes, A.L. \& Nübel, U. (2001). Phylogenetic and morphological diversity of Cyanobacteria in soil desert crusts from the colorado plateau. Applied Environmental Microbiology, 67, 1902-1910. https://doi.org/10.1128/AEM.67.4.1902-1910.2001

Guevara, R., Armesto, J.J. \& Caru, M. (2002). Genetic diversity of Nostoc microsymbionts from Gunnera tinctoria revealed by PCR-STRR fingerprinting. Microbiology Ecology, 44, 127-136. https://doi.org/10.1007/s00248-002-1019-y

Gurbuz, F., James, S.M., Aynur, G.K. \& Geoffrey, A.C. (2009). Analysis of dissolved microcystins in surface water samples from Kovada Lake, Turkey. Science of the Total Environmental, 407 (13), 4038-4046. https://doi.org/10.1016/j.scitotenv.2009.02.039

Holton, R.W., Blecker, H.H. \& Stevens, T.S. (1968). Fatty acids in blue-green algae: possible relation to phylogenic position. Science, $160 \quad$ (3827), 545-547. https://doi.org/10.1126/science.160.3827.545

Hube, A.E., Heyduck-Soller, B. \& Fischer, U. (2009). Phylogenetic classification of heterotrophic bacteria associated with filamentous marine cyanobacteria in cultures. Systematic and Applied Microbiology, 32, 256-265. https://doi.org/10.1016/j.syapm.2009.03.001

Ionescu, D., Hindiyeh, M., Malkawi, H. \& Oren, A. (2010). Biogeography of thermophilic cyanobacteria: insights from the ZerkaMa' in hot springs (Jordan). FEMS Microbiology Ecology, 72, 103-113. https://doi.org/10.1111/j.1574-6941.2010.00835.x

Katayama, T., Okamoto, S., Narikawa, R., Fujisawa, T., Kawashima, S. \& Itoh, M. (2002). Comprehensive analysis of tandem repeat sequences in cyanobacteria genome. Genome Informatics, 13, 400-401. https://doi.org/10.11234/gi1990.13.400

Keithellakpam, O.S., Oinam, A.S., Thingujam, I., Oinam, G. \& Nath, T.O. (2015). Morphology and RAPD analysis of potential cyanobacterial isolates of Loktak Lake, the only largest freshwater lake in the North-East India. Journal of Microbiology and Biotechnology, 5 (2), $46-53$.

Keshari, N., Das, S.K. \& Adhikary S.P. (2015). Identification of cyanobacterial species with overlapping morphological features by $16 \mathrm{~S}$ rRNA gene sequencing. Europen Journal of Phycology, 50 (4), 395-399. https://doi.org/10.1080/09670262.2015.1064548

Keshari, N., Das, S.K. \& Adhikary, S.P. (2016). Schmidleinema santiniketanense sp. nov. (Cyanobacteria/Cyanoprokaryota) from a building facade in Santiniketan, India. Phytotaxa, 283 (2), 181-187.

Komarek, J. \& Anagnostidis, K. (1989). Modern approach to the classification system of Cyanophytes 4-Nostocales. Algological Studies/Archiv für Hydrobiologie, 56, 247-345.

Laloui, W., Palinska, K.A., Rippka, R., Partensky, F., Marsac, T.N., Herdman, M. \& Iteman, I. (2002). Genotyping of axenic and non-axenic isolates of the genus Prochlorococcus and the OMF-'Synechococcus' clade by size, sequence analysis or RFLP of the Internal Transcribed Spacer of the ribosomal operon. Microbiology, 148 (2), 453-465. https://doi.org/10.1099/00221287-148-2-453 
Lyra, C., Soumalainen, S., Gugger, M., Vezie, C., Sundman, P., Paulin, L. \& Sivonen, K. (2001). Molecular characterization of planktonic cyanobacteria of Anabaena, Aphanizomenon, Microcystis and Planktothrix genera. International Journal of Systematic Evolutionary Microbiology, 51, 513-526. https://doi.org/10.1099/00207713-51-2-513

Lyra, C., Laamanen, M., Lehtimäki, J., Surakka, A. \& Sivonen, K. (2005). Benthic Cyanobacteria of the genus Nodularia are non-toxic, without gas vacuoles, able to glide and genetically more diverse than planktonic Nodularia. International Journal of Systematic and Evolutionary Microbiology, 55, 555-568. https://doi.org/10.1099/ijs.0.63288-0

Ma, Y., Jiao, N.J. \& Zeng, Y.H. (2004). Natural community structure of cyanobacteria in the South China Sea as revealed by rpoC1 gene sequence analysis. Letters in Applied Microbiology, 39 (4), 353-358. https://doi.org/10.1111/j.1472-765X.2004.01588.x

Margheri, M.C., Piccardi, R., Ventura, S., Viti, C. \& Giovannetti, L. (2003). Genotypic diversity of Oscillatoriacean strains belonging to the genera Geitlerinema and Spirulina determined by $16 \mathrm{~S}$ rDNA restriction analysis. Current Microbiology, 46, 359-364. https://doi.org/10.1007/s00284002-3869-4

Martinez, R., Anibarro, C. \& Fernandez, S. (2006). Genetic variability among Alexandrium tamarense and Alexandrium minutum strains studied by RAPD banding pattern analysis. Harmful Algae, 5, 599-607. https://doi.org/10.1016/j.hal.2005.11.007

Marquardt, J. \& Palinska, K.A. (2007). Genotypi c and phenotypic diversity of cyanobacteria assigned to the genus Phormidium (Oscillatoriales) from different habitats and geographical sites. Archives of Microbiology, 187 (5), 397-413. https://doi.org/10.1007/s00203-006-0204-7

Moreira, C., Ramos, V., Azevedo, J. \& Vasconcelos, V. (2014). Methods to detect cyanobacteria and their toxins in the environment. Applied Microbiology Biotechnology, 98, 8073-8082. https://doi.org/ 10.1007/s00253-014-5951-9

Muralitharan, G. \& Thajuddin, N. (2011). Rapid differentiation of phenotypically and genotypically similar Synechococcus elongatus strains by PCR fingerprinting. Biologia, 66 (2), 238-243. https://doi.org/10.2478/s11756-011-0003-8

Nabout, J.C., Rocha, B.S., Carneiro, F.M. \& Sant'Anna, Célia Leite. (2013). How many species of Cyanobacteria are there? Using a discovery curve to predict the species number. Biodiversity and Conservation, 22 (12), 2907-2918. https://doi.org/10.1007/s10531-013-0561-x

Neilan, B.A. (1995). Identification and phylogenetic analysis of toxigenic cyanobacteria by multiplex randomly amplified polymorphic DNA PCR. Applied and Environmental Microbiology, 61 (6), 2286-2291.

Neilan, B.A. (2002). The molecular evolution and DNA profiling of toxic Cyanobacteria. Current Issues Molecular Biology, 4, 1-11.

Nishihara, H., Miwa, H., Watanabe, M., Nagashima, M., Yagi, O. \& Takamura, Y. (1997). Random amplified polymorphic DNA (RAPD) analyses for discriminating genotypes of Microcystis Cyanobacteria. Bioscience Biotechnology and Biochemistry, 61 (7), 1067-1072. https://doi.org/10.1271/bbb.61.1067

Oinam, G., Tiwari, O.N. \& Sharma, G.D. (2011). PCR based molecular characterization of Cyanobacteria with special emphasis on non-heterocystous filamentous Cyanobacteria. Journal of Science and Technology, 7, 101-113. 
Okore, K., Nwaehiri, L., Mbanefo,O., Ogbulie, T. \& Ogbuka, I. (2017). The use of random amplified polymorphic DNA (RAPD) to study the genetic variation of biosurfactant producing bacteria. Academic Journal of Science, 7 (3), 267-286.

Palinska, K.A., Deventer, B., Hariri, K. \& Lotocka, M. (2011). A taxonomic study on Phormidiumgroup (cyanobacteria) based on morphology, pigments, RAPD molecular markers and RFLP analysis of the $16 \mathrm{~S}$ rRNA gene fragment. Fottea, 11 (1), 41-55. https://doi.org/10.5507/fot.2011.006

Peakall, R. \& Smouse, P.E. (2012). GenAlEx 6.5: Genetic analysis in Excel. Population genetic software for teaching and research-an update. Bioinformatics, 28 (19), 2537-2539. https://doi.org/10.1093/bioinformatics/bts460

Perumal, G.M., Ganesan, V. \& Anand, N. (2009). Identification and phylogenetic analysis of filamentous Cyanobacteria using random amplified polymorphic DNA (RAPD) fingerprinting. African Journal of Biotechnology, 8 (6), 974-978. https://doi.org/10.5897/AJB2009.000-9160

Prabakaran, M., Merinal, S., Thennarasu, V. \& Panneerselvam, A. (2011). Diversity and RAPD finger printing of cyanobacteria from fresh water habitat of Pudukkottai, Tamil Nadu. Advances in Applied Science Research, 2 (6), 101-107.

Praveen Kumar, R., Vijayan, D., Antony M.L. \& Thajuddin, N. (2009). Phylogenetic diversity of cultivable bacteria associated with filamentous non-hetrocystous marine cyanobacteria. Journal of Algal Biomass Utilization, 1 (1), 86-101.

Premanandh, J., Priya, B., Prabaharan, D. \& Uma, L. (2009). Genetic heterogeneity of the marine cyanobacterium Leptolyngbya valderiana (Pseudanabaenaceae) evidenced by RAPD molecular markers and 16S rDNA sequence data. Journal of Plankton Research, 31 (10), 1141-1150. https://doi.org/10.1093/plankt/fbp055

Rajaniemi, R., Hrouzek, P., Kastovska, K., Willame, R., Rantala, A., Hoffmann, L., Komarek, J. \& Sivonen, K. (2005). Phylogenetic and morphological evaluation of the genera Anabaena, Aphanizomenon, Trichormus and Nostoc (Nostocales, Cyanobacteria). International Journal of Systematic and Evolutionary Microbiology, 55, 11-26. https://doi.org/10.1099/ijs.0.63276-0.

Rasmussen, U. \& Svenning, M.M. (1998). Fingerprinting of cyanobacteria based on PCR with primers derived from short and long tandemly repeated repetitive sequences. Applied Environmental Microbiology, 64 (1), 265-272. https://doi.org/10.1128/AEM.64.1.265-272.1998

Redfield, E., Barns, S.M., Belnap, J., Daane, L.L. \& Kuske, C.R. (2002). Comparative diversity of composition of Cyanobacteria in three predominant soil crusts of the Colorado Plateau, FEMS Microbiology Ecology, 40, 55-63. https://doi.org/10.1111/j.1574-6941.2002.tb00936.x

Rippka, R., Deruelles, J., Waterbury, J.B., Herdman, M. \& Stanier, R.Y. (1979). Generic assignments, strain histories and properties of pure culture of cyanobacteria. Journal of General Microbiology, 111 (1), 1-61. https://doi.org/10.1099/00221287-111-1-1

Salem, M.A O., Hammad, I,A., Badea, F.A., Abdel Khalek, N.A. \& Selim, K.A. (2019). Lipid production and molecular studies of Anabaena torulosa treated with different types of stress. Egyptian Journal of Phycology, 20 (1), 84-101. 
Sarsekeyeva, F.K., Usserbaeva, A.A., Zayadan, B.K., Mironov, K.S., Sidorov, R.A., Kozlova, A.Y., Kupriyanova, E.V., Sinetova, M.A. \& Los, D.A. (2014). Isolation and characterization of a new Cyanobacterial strain with a unique fatty acid composition. Advances in Microbiology, 4, 10331043. http://dx.doi.org/10.4236/aim.2014.415114

Selvakumar, G. \& Gopalaswamy, G. (2008). PCR based fingerprinting of Westiellopsis cultures with short tandemly repeated repetitive (STRR) and highly iterated palindrome (HIP) sequences. Biologia, 63 (3), 283-288. http://dx.doi.org/10.2478/s11756-008-0065-4

Sciuto, K. \& Moro, I. (2016). Detection of the new cosmopolitan genus Thermoleptolyngbya (Cyanobacteria, Leptolyngbyaceae) using the 16S rRNA gene and 16S-23S ITS region. Molecular Phylogenetics and $\quad$ Evolution, $15-35$. http://dx.doi.org/10.1016/j.ympev.2016.08.010

Shalini, S.T., Rajinder, K.G., Sunil, P. \& Dhar, D.W. (2007). Protocol optimization for RAPD in cyanobacteria. Indian Journal of Biotechnology, 6, 549-552.

Shalini, A.E., Dhar, D.W. \& Gupta, R.K. (2008). Phylogenetic analysis of cyanobacterial strains of genus Calothrix by single and multiplex randomly amplified polymorphic DNA-PCR. World Journal of Microbiology Biotechnology, 24 (7), 927-935. http://dx.doi.org/10.1007/s11274-0079569-2

Shiels, K., Browne, N., Donovan, F., Murray, P. \& Saha, S.K. (2019). Molecular characterization of twenty-five marine Cyanobacteria isolated from coastal regions of Ireland. Biology (Basel), 8 (3), 59. https://doi.org/10.3390/biology8030059

Singh, N.K., 2008. Genetic relationship in Spirulina and related genera. PhD Thesis, IARI

Singh, N.K. \& Dhar, D.W. (2014). Diversity analysis geographically isolated strains of Spirulina and related genera. Journal of Enviromental Biology, 35 (1), 197-203.

Smit, E.J., Krueger, G.H. \& Eloff, J.N. (1983). Carotenoid composition as taxonomic character for Microcystis isolates. Journal of Limnology Society South Africa, 9 (1), 43-48.

Srivastava, A.K., Ara, A., Bhargava, P., Mishra, Y., Rai, S.P. \& Rai L.C. (2007). A rapid and costeffective method of genomic DNA isolation from cyanobacterial culture, mat and soil suitable for genomic fingerprinting and community analysis. Journal Applied Phycology, 19, 373-382. https://doi.org/10.1007/s10811-006-9144-5

Thajuddin, N. \& Muralitharan, G. (2008). Applications of PCR based fingerprinting in the phylogeny of marine cyanobacteria. Indian Hydrobiology, 11 (1), 25-41.

Weeden, N.F., Higgins, R.C. \& Gottlieb, L.D. (1982). Immunological similarity between a cyanobacterial enzyme and a nuclear DNA-encoded plastid specific isozyme from spinach. Proceedings of the Nationall Academy of Scienses of the United States of America, 79 (19), 5953-5955. https://doi.org/10.1073/pnas.79.19.5953

Williams, J.G.K., Kubelik, A.R., Livak, K.J., Rafalski, J.A. \& Tingey, S.V. (1990). DNA polymorphisms amplified by arbitrary primers are useful as genetic markers. Nucleic Acids Research, 18 (22), 6531-6535. https://doi.org/10.1093/nar/18.22.6531

Valerio, E., Pereira, P., Saker, M.L., Franca, S. \& Tenreiro, R. (2005). Molecular characterization of Cylindrospermopsis raciborskii strains isolated from Portuguese freshwaters. Harmful Algae, 4 (6), 1044-1052. https://doi.org/10.1016/j.hal.2005.03.002 
Valerio, E., Chambel, L., Paulino, S., Faria, N., Pereira, P. \& Tenreiro, R. (2009). Molecular identification, typing and traceability of cyanobacteria from freshwater reservoirs. Microbiology, 155L, 642-656. https://doi.org/10.1099/mic.0.022848-0.

Ziegler, K., Diener, A., Herpin, C., Richter, R., Deutzmann, R. \& Lockau, W. (1998). Molecular characterization of cyanophycin synthetase, the enzyme catalyzing the biosynthesis of the cyanobacterial reserve material multi-L-arginyl-polyL-aspartate (cyanophycin). European Journal of Biochemistry, 254 (1), 154-159. https://doi.org/10.1046/j.1432-1327.1998.2540154.x 